\section{Selection factors for the use of thrombolytic treatment in acute myocardial infarction: a population based study of current practice in the United Kingdom}

\author{
D Ketley, K L Woods for the European Secondary Prevention Study Group
}

Department of Pharmacy, Leicester Royal Infirmary, Leicester D Ketley

Division of Clinical Pharmacology, Department of Medicine and Therapeutics, University of Leicester, Leicester K L Woods Study participants: F Dienstl (Austria) $R$ Kala (Finland) A Leizorowicz (France) N Karatzas (Greece) $D$ Vasiliauskas (Lithuania) A Reikvam (Norway) R Seabra-Gomez (Portugal) A Agusti (Spain) L Wilhelmsen (Sweden) F Gutzwiller, J Schilling (Switzerland) $\mathrm{K}$ Woods, D Ketley (United Kingdom) Correspondence to: $\operatorname{Dr} K \mathrm{~L}$ Woods, Division of Clinical Pharmacology, Department of Medicine and Therapeutics, Clinical Sciences Building, Leicester Royal Infirmary, Leicester LE2 7LX.

Accepted for publication 2 February 1995

\begin{abstract}
Objectives-To identify and rank the factors that currently limit the use of thrombolytic treatment in patients admitted to hospital with acute myocardial infarction.

Design-Weighted sampling study with retrospective data retrieval from clinical records.

Setting-All hospitals within the Trent region providing acute general medical services.

Patients-Random sample of 420 patients admitted during February-April 1993 who had acute myocardial infarction as the main discharge diagnosis.

Main outcome measures-Treatment odds ratios (and $95 \%$ confidence intervals (CI)) for the use of thrombolysis in patient groups defined by relevant clinical characteristics.

Results-The patient population was older and less likely to have ST segment elevation on the initial electrocardiogram than patients entered into the randomised trials of thrombolysis. Thrombolytic treatment was given to $49 \%$ of patients (SE $2 \cdot 4 \%$ ). After controlling for negative associations with a history of stroke (treatment odds ratio 0.18 (95\% CI 0.04 to $0.53)$ ) and peptic ulcer (odds ratio 0.52 $(95 \%$ CI 0.26 to 1.01)) use of thrombolysis decreased with increasing patient age. This was particularly noticeable for those aged $>74$ years (odds ratio 0.17 (95\% CI 0.05 to 0.51 )) relative to those aged $<65$ years. Thrombolysis was less likely to be used in patients with ST depression (odds ratio $0.22(95 \%$ CI 0.11 to 0.41$)$ ) or bundle branch block (odds ratio 0.18 $(95 \%$ CI 0.07 to 0.44$)$ ) than in those with ST elevation on the initial electrocardiogram. Delay from symptom onset to admission was more than $12 \mathrm{~h}$ in $15 \%$ of patients.

Conclusions-The patient population admitted to hospital with acute myocardial infarction differs in several respects from the samples that have been included in the trials of thrombolysis. The main factors limiting wider use of thrombolysis are diagnostic uncertainty at admission and delayed presentation. Perceived
\end{abstract}

clinical contraindications to treatment are of lesser importance. There is evident reluctance to use thrombolytic treatment in older patients, who were substantially under-represented in the clinical trials.

\section{(Br Heart $\mathcal{F} 1995 ; 74: 224-228$ )}

Keywords: acute myocardial infarction; thrombolytic treatment; selection factors for thrombolysis

Large randomised trials have shown conclusively that the risk of death after acute myocardial infarction is reduced by thrombolytic treatment. ${ }^{1}$ Despite general acceptance of its efficacy, however, only a minority of patients admitted to hospital with acute myocardial infarction receive this form of treatment. A study relating the supply of thrombolytic drugs to hospital admissions in the Trent region showed that thrombolytic treatment was adopted slowly during the five years after publication of the major trials, with wide variations in rates of use between districts. ${ }^{2}$ By 1991-1992, when a plateau seemed to have been reached, use of thrombolytic drugs was sufficient to treat at most $49 \%$ of all admitted patients with acute myocardial infarction as their main diagnosis. This is consistent with other population based data from the United Kingdom ${ }^{3}$ and higher than recent estimates of $20-23 \%$ from the United States (WD Weaver et al, 43rd annual scientific session, Atlanta, USA, 1994). ${ }^{4}$ Variation in thrombolytic use between districts showed a highly significant association with extent of earlier participation in multicentre trials of thrombolysis, but the ecological study design (in which the unit of analysis is a population rather than the individual patient) did not allow the influence of patient variables to be examined. ${ }^{2}$

Patients entering clinical trials are a nonrandom sample of the clinical population that they are intended to represent, and the clinical characteristics of the latter are poorly defined. The limited use of thrombolytic treatment may reflect important differences between "typical" patients and trial patients, or a restrictive interpretation of indications and contraindications by clinicians. To have broad validity, analyses of clinical decision making 
must be based on properly constructed samples drawn from large populations. We have therefore examined the clinical characteristics and management of a random sample of all patients admitted to hospitals within the Trent region in whom acute myocardial infarction was the main diagnosis. The study was not designed to compare clinical management with a predefined protocol of "optimum treatment" or to examine treatment outcome. The aims were to analyse the determinants of thrombolytic use and to compare the patient population with the samples which have been included in the major thrombolytic trials. A common protocol was agreed by the European Secondary Prevention Study Group so that the data can ultimately be used to examine international variations in the management of acute myocardial infarction.

\section{Patients and methods}

STUDY POPULATION

Trent region has a population of 4.7 million (8.5\% of the total United Kingdom population) and includes the counties of Derbyshire, Leicestershire, Lincolnshire, Nottinghamshire, and South Yorkshire. It is demographically representative of the United Kingdom and ischaemic heart disease mortality within the region is very close to the national average. Each year there are approximately 10500 admissions to hospitals within the region in whom the main (discharge) diagnosis is acute myocardial infarction. Admission rates with this diagnosis in the 12 health districts range from 1.6 to 3.7 per 1000 population per year.

\section{STUDY SAMPLE}

The sampling frame consisted of patients in the population served by Trent Regional Health Authority who were discharged from hospital during February-April 1993 with acute myocardial infarction as the main discharge diagnosis. Patients who died in hospital were included. The sample size was chosen to give adequate precision (SE $2.5 \%$ ) for a predicted thrombolysis rate of $50 \%$. The sample requirement was divided between the 12 health districts in the region in proportion to the number of patients admitted with acute myocardial infarction during one month of the study time frame.

Listings of discharges for each district in the study time frame were provided by the Trent regional statistical department. The required number of patients (plus $20 \%$ to allow for non-availability of clinical records) was drawn from each district list by random sampling. For districts with more than one hospital receiving acute admissions, the sampling procedure ensured that the contribution from each hospital was proportional to its share of coronary admissions.

DATA RETRIEVAL

Records were reviewed on site about four months after the index admission. The notes were available for all but $12 \%$ of the sample, which were out of file for a range of reasons unlikely to cause significant bias. A standard data set was abstracted by one investigator and over $99 \%$ of data elements were available. The data included information on medical history, presenting features, and treatment received. The retrospective design was used to avoid possible bias which might arise if physicians were aware which patients were to be included in the study. No identifiers of patient, hospital, or district were entered into the study database; all analyses were performed on the entire regional sample. The feasibility of the design was confirmed in a pilot project in one hospital before the main study began.

\section{STATISTICAL ANALYSIS}

Associations between thrombolytic treatment and patient characteristics were estimated by the treatment odds ratio and its $95 \%$ confidence interval (CI) and tested by the $\chi^{2}$ test. Stratified analyses used the Mantel Haenzsel procedure. The comparison category for the odds ratio is stated for each analysis.

\section{Results}

\section{PATIENT CHARACTERISTICS}

Data were collected on 420 patients with a mean age of 68 years (65 years for men and 74 years for women). Acute myocardial infarction had been diagnosed or suspected at admission in $89 \%$ of the sample; $53 \%$ of the total had been admitted to a coronary care unit. Delay from symptom onset to admission (fig) exceeded $12 \mathrm{~h}$ in $15 \%$ of patients. Table 1 gives the clinical characteristics of the study sample with the corresponding data from a summary of all large thrombolytic trials. ${ }^{1}$ Because of its influence on United Kingdom practice, data for the second international study of infarct survival (ISIS-2) 5 are also shown separately. In comparison with this random sample, patients included in the major thrombolytic trials were younger $(P<$ $0.0001)$, more likely to have ST elevation on the admission electrocardiogram $(\mathrm{P}<$ 0.0001 ), but less likely to have had previous myocardial infarction $(P=0.012)$. Women were under-represented in the trials $(\mathrm{P}<$ $0 \cdot 0001)$.

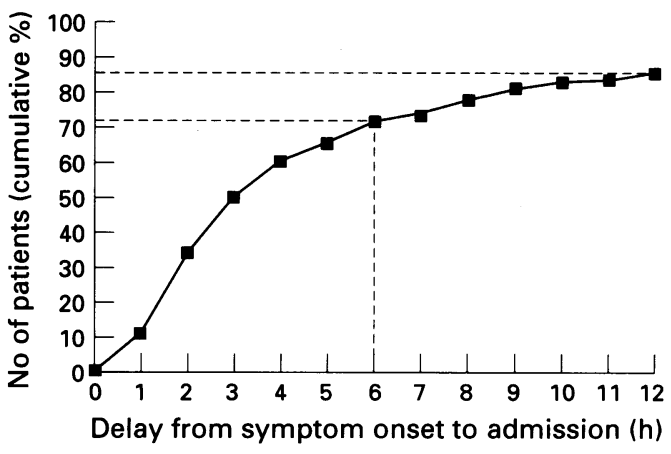

Cumulative distribution of delay between symptom onset and hospital admission $(n=414)$. 
Table 1 Clinical characteristics for the study sample compared with pooled data for all patients $(n=58600)$ in controlled trials of thrombolysis in which more than 1000 patients were randomised (1) and with ISIS-2 (19)

\begin{tabular}{|c|c|c|c|c|c|}
\hline & & \multicolumn{4}{|l|}{ Patients (\%) } \\
\hline & & \multicolumn{3}{|c|}{ Study sample All trials } & ISIS-2 \\
\hline \multicolumn{6}{|l|}{ Age (years) } \\
\hline$<65$ & & \multirow{2}{*}{$\begin{array}{l}35 \\
32\end{array}$} & \multicolumn{2}{|l|}{61} & 64 \\
\hline $65-74$ & & & 29 & & 28 \\
\hline$>74$ & & 33 & 10 & & 8 \\
\hline \multicolumn{6}{|l|}{ Sex } \\
\hline Male & & \multirow{2}{*}{$\begin{array}{l}67 \\
33\end{array}$} & \multirow{2}{*}{\multicolumn{2}{|c|}{$\begin{array}{l}76 \\
24\end{array}$}} & 77 \\
\hline Female & & & & & 23 \\
\hline \multicolumn{6}{|c|}{ Previous myocardial infarction } \\
\hline Yes & & \multirow{2}{*}{$\begin{array}{l}25 \\
75\end{array}$} & \multirow{2}{*}{$\begin{array}{l}20 \\
80\end{array}$} & & \multirow{2}{*}{$\begin{array}{l}17 \\
83\end{array}$} \\
\hline No & & & & & \\
\hline \multirow{2}{*}{$\begin{array}{l}\text { Time } \\
\text { from } \\
\text { onset }(h)\end{array}$} & \multicolumn{2}{|c|}{ Cumulative \% } & & \multirow{2}{*}{\multicolumn{2}{|c|}{$\begin{array}{l}\text { Cumulative \% } \\
\text { to } \\
\text { randomisation }\end{array}$}} \\
\hline & Admission & \multicolumn{2}{|c|}{ Thrombolysis } & & \\
\hline $0-1$ & 11 & 0 & & 6 & 4 \\
\hline $2-3$ & 50 & 28 & & 34 & 30 \\
\hline $4-6$ & 72 & 71 & & 62 & 63 \\
\hline $7-12$ & 85 & 94 & & 84 & 86 \\
\hline $13-24$ & 93 & 99 & & 100 & 100 \\
\hline \multicolumn{6}{|c|}{ Electrocardiogram } \\
\hline \multirow{2}{*}{\multicolumn{2}{|c|}{ ST elevation }} & \multirow{2}{*}{$\begin{array}{l}57 \\
15\end{array}$} & \multirow{2}{*}{\multicolumn{2}{|c|}{$\begin{array}{r}68 \\
7\end{array}$}} & 61 \\
\hline & & & & & 7 \\
\hline BBB & & 7 & \multicolumn{2}{|l|}{4} & 4 \\
\hline \multicolumn{2}{|c|}{ Normal/other } & 21 & \multicolumn{2}{|l|}{22} & 27 \\
\hline
\end{tabular}

* BBB, bundle branch block.

Table 2 Association between the use of thrombolysis and documented medical history

\begin{tabular}{|c|c|c|c|c|}
\hline & $n$ & $(\%)$ & $\begin{array}{l}\text { Thrombolysis odds ratio } \\
\text { ( } 95 \% \text { confidence interval) }\end{array}$ & $p$ value \\
\hline $\begin{array}{l}\text { Stroke } \\
\text { Never } \\
\text { Any time } \\
\text { Distant (> } 3 \text { months) }\end{array}$ & $\begin{array}{r}394 \\
26 \\
20\end{array}$ & $\begin{array}{l}(94) \\
(6) \\
(5)\end{array}$ & $\begin{array}{l}1.0 \\
0.18(0.04-0.53) \\
0.24(0.06-0.77)\end{array}$ & $\begin{array}{l}0 \cdot 001 \\
0.014\end{array}$ \\
\hline $\begin{array}{l}\text { Peptic ulcer } \\
\text { Never } \\
\text { Any time } \\
\text { Distant (>3 months) }\end{array}$ & $\begin{array}{r}371 \\
49 \\
33\end{array}$ & $\begin{array}{l}(88) \\
(12) \\
(8)\end{array}$ & $\begin{array}{l}1.0 \\
0.52(0.26-1.01) \\
0.93(0.42-2 \cdot 02)\end{array}$ & $\begin{array}{l}0 \cdot 06 \\
0.98\end{array}$ \\
\hline $\begin{array}{l}\text { Recent trauma/surgery } \\
\text { No } \\
\text { Yes }\end{array}$ & $\begin{array}{r}408 \\
12\end{array}$ & $\begin{array}{l}(97) \\
(3)\end{array}$ & $\begin{array}{l}1.0 \\
0.09(0.0-0.64)\end{array}$ & 0.01 \\
\hline $\begin{array}{l}\text { Cardiopulmonary resusc } \\
\text { No } \\
\text { Yes }\end{array}$ & $\begin{array}{r}397 \\
23\end{array}$ & $\begin{array}{l}(95) \\
(5)\end{array}$ & $\begin{array}{l}1.0 \\
0.97(0.38-2.46)\end{array}$ & 0.89 \\
\hline
\end{tabular}

Table 3. Association between use of thrombolysis and electrocardiogram changes recorded at admission ${ }^{\star}$

\begin{tabular}{|c|c|c|c|c|c|}
\hline & \multirow[b]{2}{*}{$n \dagger$} & \multicolumn{2}{|c|}{ Thrombolysis } & \multirow{2}{*}{$\begin{array}{l}\text { Odds ratio ( } 95 \% \\
\text { confidence interval) }\end{array}$} & \multirow[b]{2}{*}{ p Value } \\
\hline & & $n$ & $(\%)$ & & \\
\hline $\begin{array}{l}\text { Electrocardiogram } \\
\text { ST elevation } \\
\text { ST depression } \\
\text { BBB } \\
\text { Other }\end{array}$ & $\begin{array}{r}235 \\
62 \\
30 \\
89\end{array}$ & $\begin{array}{r}165 \\
21 \\
9 \\
8\end{array}$ & $\begin{array}{l}(70) \\
(34) \\
(30) \\
(9)\end{array}$ & $\begin{array}{l}1.00(-) \\
0.22(0.11-0.41) \\
0.18(0.07-0.44) \\
0.04(0.02-0.09)\end{array}$ & $\begin{array}{l}-<0.0001 \\
<0.0001 \\
<0.0001\end{array}$ \\
\hline
\end{tabular}

*Patients with several electrocardiogram abnormalities were assigned to the highest electro-

cardiogram category.
tElectrocardiogram not available for four patients. $\mathrm{BBB}$, bundle branch block.
USE OF THROMBOLYSIS

Thrombolytic treatment was given to $49 \%$ of patients. Only two patients were treated outside hospital; both received anistreplase. Streptokinase was used in 192 patients and alteplase in 10. A history of stroke at any time, peptic ulcer symptoms in the preceding three months, or recent trauma or surgery were all associated with significantly lower use of thrombolysis (table 2). In contrast, there was no evidence that a more distant history of peptic ulceration or cardiopulmonary resuscitation during the index admission discouraged thrombolysis.

Table 3 gives the influence of the initial electrocardiogram on treatment. Any electrocardiogram pattern other than ST elevation was associated with a highly significant reduction in thrombolytic use. This included bundle branch block, for which the treatment odds ratio was 0.18 (95\% CI $0.07-0.44)$. The category other includes a normal initial electrocardiogram.

The effect of age on treatment was controlled for possible confounding by stroke or recent peptic ulcer history, or by later presentation among the elderly. After exclusion of patients with any of these factors, a negative association between increasing age and thrombolytic use was evident among patients with ST elevation on admission (table 4). This was highly significant for patients aged $>74$ years. The association between patients' sex and their likelihood of receiving thrombolysis was confounded by age, and was nonsignificant after adjustment for this factor $(P=0 \cdot 16)$.

\section{PRINCIPAL FACTORS IN NON-USE OF}

THROMBOLYSIS

Of the 216 patients not given a thrombolytic drug, the time of symptom onset was greater than $12 \mathrm{~h}$ before admission or indeterminate in $63(29 \%)$. In $114(75 \%)$ of the remaining 153 there were clear diagnostic difficulties: acute myocardial infarction was not listed in the differential diagnosis at admission in 30 and there was no ST elevation in the initial electrocardiogram in 84 (although acute myocardial infarction was suspected). If these patients are excluded there remain only 12 with definite contraindications to thrombolysis and 27 without clear reason(s) for the withholding of thrombolytic treatment. If the latter $(13 \%$ of all non-thrombolysed patients) had been treated, the overall thrombolysis rate would have risen only from $49 \%$ to $55 \%$.

In any individual patient, more than one factor may contribute to the decision not to use thrombolysis. However, it is possible to infer from this sample a rank order of factors. Lack of a clear diagnosis at admission is the most important; the next is late presentation; and the least important is the presence of clear clinical contraindications to this form of treatment. Age is evidently an additional influential factor (table 4). 
Table 4 Association of thrombolytic use with age, and with sex after adjustment for age (Mantel Haenzsel odds ratio in 5 year strata), in patients with ST elevation admitted within $12 \mathrm{~h}$ of symptom onset and without history of stroke or recent peptic ulcer (<3 months)

\begin{tabular}{|c|c|c|c|c|c|}
\hline & \multirow[b]{2}{*}{$n$} & \multicolumn{2}{|c|}{ Thrombolysis } & \multirow{2}{*}{$\begin{array}{l}\text { Odds ratio } \\
\text { ( } 95 \% \\
\text { confidence interval) }\end{array}$} & \multirow[b]{2}{*}{ p Value } \\
\hline & & $n$ & $(\%)$ & & \\
\hline $\begin{array}{c}\text { Age (years) } \\
<65 \\
65-74 \\
>74\end{array}$ & $\begin{array}{l}78 \\
59 \\
48\end{array}$ & $\begin{array}{l}72 \\
52 \\
32\end{array}$ & $\begin{array}{l}(92) \\
(88) \\
(67)\end{array}$ & $\begin{array}{l}1.00(-) \\
0.62(0.16-2.30) \\
0.17(0.05-0.51) \\
\quad \chi^{2} \text { for trend }\end{array}$ & $\begin{array}{l}\overline{0.41} \\
<0.001 \\
<0.001\end{array}$ \\
\hline $\begin{array}{l}\text { Sex } \\
\text { Male } \\
\text { Female }\end{array}$ & $\begin{array}{r}135 \\
50\end{array}$ & $\begin{array}{r}121 \\
35\end{array}$ & $\begin{array}{l}(90) \\
(70)\end{array}$ & $\begin{array}{l}1 \cdot 00 \\
0.45^{\star}(0 \cdot 16-1 \cdot 28)\end{array}$ & $0 \cdot 16$ \\
\hline
\end{tabular}

^Age adjusted.

\section{DIAGNOSTIC UNCERTAINTY}

Diagnostic difficulty was the main factor limiting the use of thrombolysis in the Trent sample. In $21 \%$ of patients not given thrombolytic treatment the diagnosis of acute myocardial infarction was not noted as a possibility at admission. Even when acute myocardial infarction was suspected, clinicians were clearly reluctant to give thrombolysis in the absence of ST elevation. This electrocardiogram feature may be transient or intermittent, ${ }^{14}$ perhaps because of spontaneous reperfusion. It has been argued ${ }^{15}$ that thrombolytic treatment should be given on the basis of strong clinical suspicion of acute myocardial infarction even without ST elevation, although the trials have not shown mortality benefit from thrombolytic treatment of patients with a normal electrocardiogram or ST depression. ${ }^{1}$ Bundle branch block on the initial electrocardiogram was associated with a low likelihood of receiving a thrombolytic drug, even though such patients benefited from thrombolysis in the trials. A bundle branch block makes the electrocardiogram uninformative in the diagnosis of acute infarction; the trial patients with this electrocardiogram feature probably had particularly strong clinical evidence for the diagnosis.

DELAY FROM SYMPTOM ONSET TO ADMISSION Delayed presentation reduces the population benefit to be had from thrombolysis in two ways: it increases the proportion of patients admitted too late to be treated and reduces the efficacy of treatment in the remainder.

In the trials, each hour of delay lessened the absolute reduction in 35 day mortality attributable to thrombolysis by 1.6 (SD 0.6 ) deaths per 1000 patients treated. ${ }^{1}$ The balance of risk and benefit for thrombolytic treatment given beyond $12 \mathrm{~h}$ from symptom onset is debated and this is a widely adopted cut off for such treatment. Late presentation beyond this $12 \mathrm{~h}$ limit will exclude $15 \%$ of patients from thrombolysis.

SCOPE FOR WIDER USE OF THROMBOLYSIS

There is evidence of a consensus on the main clinical contraindications to thrombolytic treatment (table 2), which were not a substantial limiting factor to the wider application of thrombolysis. There are several ways in which the public health impact of thrombolysis might be improved. First, better early diagnosis of myocardial infarction may be possible using serial electrocardiograms in the first few hours of admission to increase the likelihood of detecting ST segment elevation. The possible role of rapid cardiac enzyme assays is also being studied. ${ }^{16}$ Second, better health education (particularly for those with known ischaemic heart disease) is needed to shorten admission delay times. ${ }^{17} 18$ Third, the issue of thrombolysis in patients aged $>74$ years must be resolved as this group comprises one third of all admissions with acute myocardial infarction in the United Kingdom.

\begin{abstract}
that clinicians have a slightly lower the diagnosis in women because the incidence is smaller. despite strong arguments put forward against A lower use of thrombolysis in women than also noted in this sample, but the negative association was non-significant after adjus ment for age. Similar confounding by age has
\end{abstract}

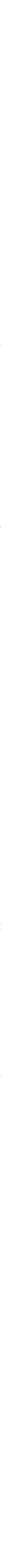


The European Secondary Prevention Study is funded by a CEC grant under the Third Framework Biomedicine and Health programme. We thank Mrs S Fletcher, Miss S Wright, the staff of the statistical section, Trent Regional Health Authority, and the medical records officers of the contributing hospitals for their help, and Professor R Alderslade for his support.

1 Fibrinolytic Therapy Trialists (FTT) Collaborative Group. Indications for fibrinolytic therapy in suspected acute myocardial infarction: collaborative overview of early mortality and major morbidity results from all randomised trials of more than 1000 patients. Lancet 1994; 343:311-22.

2 Ketley D, Woods KL. Impact of clinical trials on clinical practice: example of thrombolysis for acute myocardial practice: example of thrombolysis
infarction. Lancet 1993;342:891-4.

3 Norris RM, Roy S, Dixon GF. What proportion of patients with acute myocardial infarction should receive thrombolytic therapy? [abstr] Br Heart f 1994;71:P40.

4 Every NR, Larson EB, Litwin PE, Maynard C, Fihn SD, Eisenberg MS, et al. The association between on-site cardiac catheterization facilities and the use of coronary angiography after acute myocardial infarction. $N$ Engl $f$ Med 1993;329:546-51.

5 ISIS-2 (Second International Study of Infarct Survival) Collaborative Group. Randomised trial of intravenous streptokinase, oral aspirin, both, or neither among 17187 cases of suspected acute myocardial infarction: ISIS-2. Lancet 1988;ii:349-60.

6 AIMS Trial Study Group. Effect of intravenous APSAC on mortality after acute myocardial infarction: preliminary report of
7 Wilcox RG, Von der Lippe G, Jensen G, Olsson CG, Hampton JR, Skene AM. Trial of tissue plasminogen activator for mortality reduction in acute myocardial infarction (Anglo-Scandinavian Study of Early Thrombolysis ASSET). Lancet 1988;ii:525-30.

8 Simoons ML, Maggioni AP, Knatterud G, Leimberger JD, De Jaegere $\mathrm{P}$, Van Domberg $\mathrm{R}$, et al. Individual risk assessment for intracranial haemorrhage during thrombolytic therapy. Lancet 1993;342:1523-8.

9 Haigh R, Castleden C, Woods K, Fletcher S, Bowns I, Gibson $M$, et al. Management of myocardial infarction in the elderly: admission and outcome on a coronary care unit. Health Trends 1991;23:154-7.

10 Elder AT, Fox KA. Thrombolytic treatment for elderly patients. BMF 1992;305:846-7.

11 Wilkinson P, Laji K, Ranjadayalan K, Parsons L, Timmis $\mathrm{AD}$. Acute myocardial infarction in women: survival andysis in first six months. BMF 1994;309:566-9.

12 Clarke KW, Gray D, Keating NA, Hampton JR. Do women with acute myocardial infarction receive the women with acute myocardial infarction receiv
same treatment as men? $B M \mathcal{F} 1994 ; 309: 563-6$.

13 Hannaford PC, Kay CR, Ferry S. Agism as explanation fo sexism in provision of thrombolysis. BMF 1994;309:573.

14 Adams J, Tent R, Rawles J on behalf of the GREAT Group. Earliest evidence of myocardial infarction: implications for thrombolytic treatment. BMf 1993;307: 409-13.

15 Rawles J. Deciding who should have thrombolysis [letter] $B M 7$ 1994;308:59-60.

16 Hamm CW. New serum markers for acute myocardial infarction. N Engl f Med 1994;331:607-8.

17 Weston CFM, Penny WJ, Julian DG. Guidelines for the early management of patients with myocardial infarcearly management of patients
tion. $B M \mathcal{F} 1994 ; 308: 767-71$.

18 Birkhead JS. Time delays in provision of thrombolytic treatment in six district hospitals. BMF 1992;305:445-8. 